\title{
Introduction. Deinstitutionalisation and the Pathways of Post-War Psychiatry in the Western World
}

\author{
Despo Kritsotaki ${ }^{1}$, Vicky Long ${ }^{2}$ and Matthew Smith ${ }^{3}$ \\ ${ }^{1}$ Department of History, University of Crete, Heraklion, Greece \\ ${ }^{2}$ Centre for the Social History of Health and Healthcare, Glasgow Caledonian \\ University, Glasgow, UK \\ ${ }^{3}$ Department of History, University of Strathclyde, Glasgow, UK
}

Near the small village of Gartcosh, located in the north-eastern quadrant of the greater Glasgow conurbation, there is an imposing two-towered gothic building that used to serve as the Main Administration Building of Gartloch Hospital. Surrounded by a fence, designed to keep people out, rather than to keep them in, its windows are either broken or boarded up. Inside, what is left of the floors is strewn with detritus, ranging from broken bits of furniture and torn curtains to crumbling plaster and bent nails. It is only when one looks up to the elaborate arched and buttressed ceiling, painted in shades of aquamarine, scarlet and vermillion, that a hint of the former grandeur of the place becomes apparent.

Established in 1896 by the City of Glasgow and District Lunacy Board, Gartloch Hospital was one of dozens of Scottish psychiatric institutions built between the end of the eighteenth century and the middle of the twentieth century. It would exist for exactly 100 years, typically housing between 500 and 800 patients. Although it functioned primarily as a psychiatric facility for the city's poor, as with similar institutions, it also served other functions, including a tuberculosis sanitaria soon after it opened, and as an Emergency Medical Services hospital during the First World War. Just prior to its closure in 1996, it was used as the set of the BBC drama Takin' Over the Asylum, starring Ken Stott and David Tennant.

The passage of time, alongside a renewed interest in heritage and a consequent newfound appreciation for these buildings' architectural qualities, has paved the way 
for redevelopment of these sites, slowly disentangling their architectural form from their erstwhile function. ${ }^{1}$ Today, as with many former psychiatric hospitals, some of the former buildings at Gartloch have been converted into luxury apartments, and the grounds are being transformed into a housing estate. On the website for Gartloch Village, ironically described as being 'far from maddening crowd', the developers mention that a hospital was built here in 1896 (and 'immediately hailed as a Victorian architectural masterpiece'), but fail to mention its numerous psychiatric patients, focussing instead on its role treating 'returning war heroes'. ${ }^{2}$ This approach is echoed in other asylum redevelopment projects. Friern Hospital, which opened to pauper patients in 1851 as Colney Hatch Asylum and at one time was England's largest asylum, closed in 1993. It reopened in 1995 as Princess Park Manor, a self-contained luxury housing development marketed as somewhere that you 'never need to leave'. A

${ }^{1}$ B. Franklin (2002) 'Hospital- Heritage - Home: Reconstructing the Nineteenth Century Lunatic Asylum', Housing, Theory and Society, 19, 170-84. Peter Bartlett observed that the ornate features found in pauper asylum architecture reflected the survival of a charitable strand of ideology in post 1834 Poor Law thought: see P. Bartlett (1999) 'The Asylum and the Poor Law: The Productive Alliance' in J. Melling and B. Forsthye (eds.) Insanity, Institutions and Society, 1800-1914 (London and New York: Routledge), pp. 48-67.This has facilitated the repurposing of these sites from pauper institutions to luxury housing.

${ }^{2}$ http://gartlochvillage.co.uk/why-choose-gartloch-village/ 
commemorative plaque in the reception area is the only indication of the site's former purpose. $^{3}$

While the developers of Gartloch Village may wish to obscure what the primary function of Garloch Hospital was for a century, the presence of the gloomy Main Administration Building, its red brick tarnished by soot, tells a different story. In fact, it tells two stories. On the one hand, it reveals a Glaswegian episode in the history of psychiatric institutionalisation, a period when hundreds of thousands of people deemed to be mentally ill were housed in psychiatric asylums. But, on the other hand, the decrepit Main Administration Building also hints at the story of what happened (and what continues to happen) next, when such institutions began to be shut during the second half of the twentieth century. Unlike the history of asylums, which dominated the historiography of mental illness and psychiatry until the 1990s and continue to attract the attention of both scholars and students, the history of deinstitutionalisation is only beginning to be told. On a dreich Glasgow day, the two gothic towers of the Main Administration Building seem to ask: How did this happen? Why did it happen? What happened to the people who used to reside behind these walls? And what happens to those today who might have found themselves behind these walls in times past?

This volume is an attempt to address some of these questions. It analyses the ideas that spurred deinstitutionalisation, charts the process of psychiatric reform in the postwar period, examines how asylum and therapeutic spaces changed for the mentally ill and assesses the ongoing legacy of deinstitutionalisation. Focussing solely on the

\footnotetext{
${ }^{3}$ B. Taylor (2011) 'The Demise of the Asylum in Late Twentieth-Century Britain: A Personal History', Transactions of the Royal Historical Society, 21, 193-215; 214.
} 
western world, the book explores the challenges faced by various jurisdictions in transforming psychiatric theory into practice.

Indeed, this is a theme that knits many of the chapters together. Psychiatry is a medical discipline where theories have abounded, more so than any other field of medicine. Even when these theories have begotten therapies, ranging from lobotomy and psychopharmacology to psychoanalysis and cognitive behavioural therapy, vigorous debates have followed about whether such practical applications were efficacious, ethical, cost-effective or even humane. Such was the case with deinstitutionalisation and continues to be so. Many of the ideas that provided the framework for the closure and reformation of psychiatric hospitals were well-intended and embedded in widely accepted theory, but were problematic to apply in practice or required the sort of structural and political support that was difficult to maintain over time.

\section{Defining Deinstitutionalisation}

Deinstitutionalisation is commonly defined as the process that occurred when mental health care shifted from being based in residential asylums to becoming primarily an outpatient service during the second half of the twentieth century. Rather than living in asylums for possibly extensive periods of time, most patients were expected to live in their home communities, receiving psychiatric care and treatment in clinics and general hospitals. Others have added that the process also involved the integration of remaining psychiatric institutions and their functions with that other health services, in order to remove the often negative consequences of institutional life on patients, such as 
passivity, loss of autonomy and stigma. ${ }^{4}$ According to the World Health Organization (WHO), however, the process was meant to be more complex than mere 'dehospitalization' or 'simply reducing hospital beds'. ${ }^{5}$ It was also intended to involve establishing high-quality care in community settings, providing comprehensive social services support to both patients and their families and maintaining adequate acute inpatient services, as well as long-stay facilities. ${ }^{6}$

But deinstitutionalisation was more than merely a process of transitioning care and support from residential institutions to the community; it also constituted a significant philosophical sea-change. It represented what was supposed to be a momentous transformation in the relationship between society and the mentally ill, in how mental illness was conceptualised and in how it was treated. Deinstitutionalisation cast aside the idea that the mentally ill had to be set apart from society, whether it be for their protection, society's protection (or convenience) or because secluded, secure institutions were deemed to be the most therapeutically valuable spaces for recovery. Shut away in massive institutions, such as Milledgeville, Georgia's Central State Hospital, where 12,000 patients resided as late as the $1960 \mathrm{~s}$, or solitarily in a private house, the mentally ill were cast in the role of the most undesirable 'other', a vision of

${ }^{4}$ See W. Brunton (2003) 'The Origins of Deinstitutionalisation in New Zealand', Health and History, 5:2, 75-103.

${ }^{5}$ World Health Organization (2014) Innovation in Deinstitutionalization: A WHO Expert Survey (Geneva: World Health Organization), p. 17, http://apps.who.int/iris/bitstream/10665/112829/1/9789241506816_eng.pdf, accessed 4 March 2016.

${ }^{6}$ Ibid. 
humanity best kept hidden. ${ }^{7}$ Deinstitutionalisation was meant to correct this perceived wrong. Physical reintegration was supposed to go hand in hand with a re-evaluation of the worth of people who suffer from mental illness and their full inclusion within society as citizens; the stigmatised identity of mental patient was to be discarded. In practice, this goal has only been partially achieved, demonstrating the ambiguities and inadequacies of government policy towards people suffering from mental illness, which has failed to secure their social and economic equality. ${ }^{8}$

For patients, the asylum, mental hospital or psychiatric institution (these terms and others will be used interchangeably in this book) would cease to be the site around which their lives literally and figuratively revolved. Instead, fortunate patients would be treated in a range of smaller and more community-oriented facilities, ranging from therapeutic communities and half-way houses to community mental health clinics and in private and public medical practices. But, as WHO and many other organisations and individuals have acknowledged, deinstitutionalisation has often amounted to

\footnotetext{
${ }^{7}$ A. Scull (2015) Madness in Civilization: From the Bible to Freud, from the Madhouse to Modern Medicine (London: Thames and Hudson), p. 361; S. Wise (2012) Inconvenient People: Lunacy, Liberty and the Mad-Doctors in Victorian England (London: The Bodley Head); E. Said (1978) Orientalism (New York: Pantheon); M. Foucault (1961) Madness and Civilization: A History of Insanity in the Age of Reason, translated by F. Howard (New York: Vintage).

${ }^{8}$ P. Barham (1997) Closing the Asylum: The Mental Patient in Modern Society (London: Penguin); V. Long (2014) Destigmatising Mental Illness? Professional Politics and Public Education in Britain, 1870-1970 (Manchester: Manchester University Press).
} 
dehospitalisation, with shameful repercussions. Less fortunate have not have found themselves deinstitutionalised as much as 'transinstitutionalised' into the criminal justice system. ${ }^{9}$ A recent article in The Atlantic estimated that 400,000 inmates in American prisons had mental health problems, citing a National Alliance on Mental Illness estimate that between 25 and 40 per cent of mentally ill Americans will find themselves behind bars at some time in their life. ${ }^{10}$ Thousands of others have found themselves homeless, living in the street or in temporary accommodation. In 2007, the United States Department of Housing and Urban Development (HUD) reported that 39 per cent of the nation's 600,000 homeless people reported having a mental health problem, and that between 20 and 25 per cent met the criteria for serious mental illness. ${ }^{11}$ Although the incarceration and homelessness of the mentally ill are issues of

${ }^{9}$ Although it took post-war deinstitutionalisation for transinstitutionalisation to occur on a major scale, the British psychiatrist Lionel Penrose (1898-1972) first theorised that an inverse relationship existed between the population of prisons and asylums during the 1930s. As the population in the one increases, the population of the other decreases. L. S. Penrose (1939) 'Mental Disease and Crime: Outline of a Comparative Study of European Statistics', British Journal of Medical Psychology, 18, 1-15.

${ }^{10}$ M. Ford (8 June 2015) 'America's Largest Mental Hospital is Jail', The Atlantic, http://www.theatlantic.com/politics/archive/2015/06/americas-largest-mentalhospital-is-a-jail/395012/, accessed 3 March 2016.

${ }^{11}$ U.S. Department of Housing and Urban Development Office of Policy Development and Research (2007) The Applicability of Housing First Models to Homeless Persons with Serious Mental Illness (Washington, DC: U.S. Department of Housing and Urban 
contemporary relevance, both have been recognised as consequences of deinstitutionalisation since the $1970 \mathrm{~s}^{12}$ As had been the case in the pre-institution era, families in many countries have been left to fill in the cracks left gaping by an inadequate mental health system, providing much of the care formerly provided by the state or private hospital. ${ }^{13}$

\section{Precursors and Drivers of Deinstitutionalisation}

Deinstitutionalisation began in most countries during the years following the Second World War and reached its height between the 1960s and the 1990s, though the process has continued apace in many jurisdictions. ${ }^{14}$ It could be argued, however, that the

Development Office of Policy Development and Research), https://www.huduser.gov/portal/publications/hsgfirst.pdf, accessed 3 March 2016.

${ }^{12}$ S. Trotter and B. Kuttner (24 February 1974) 'The Mentally Ill: From Back Wards to Back Alleys', Washington Post; S. Stelovich (1978) 'From the Hospital to the Prison: A Step Forward in Deinstitutionalization?', Hospital and Community Psychiatry, 30, 618-20; G.E. Whitmer (1980) 'From Hospitals to Jails: The Fate of California's Deinstitutionalized Mentally Ill', American Journal of Orthopsychiatry, 50, 65-75; J. Arboleda-Florez and H.L. Holley (1988) 'Criminalization of the Mentally Ill: Part II: Initial Detention', Canadian Journal of Psychiatry, 33, 87-95.

${ }^{13}$ Scull (2015) Madness in Civilization, pp. 85, 121, 268-69; WHO, Innovation in Deinstitutionalization; W. Doll (1976) 'Family Coping with the Mentally Ill: An Unanticipated Problem of Deinstitutionalization', Hospital and Community Psychiatry, $27,183-85$.

${ }^{14} \mathrm{http}: / /$ www.desmoinesregister.com/story/news/health/2015/10/08/branstads-mentalhospital-closures-debated-court/73611220/; 
origins of deinstitutionalisation stretch back into the era of asylum expansion in the mid nineteenth century. Mental hospitals were criticised for being costly, inefficient and even detrimental to the wellbeing of patients, to which the scandalous cases of patients such as Ebenezer Haskell (1805-1892) or the intrepid investigative reporter Nellie Bly (1864-1922) attest. ${ }^{15}$ In 1845, a group of former asylum patients in Britain established the Alleged Lunatics' Friend Society, which sought to foster public sympathies, improve asylum conditions, and prevent wrongful confinement. ${ }^{16}$ Another example of how asylums were beginning to be questioned is the French 'anti-psychiatry' campaign of the 1860s, which focused on wrongful confinement, the poor asylum and the excessive power of the psychiatric profession. ${ }^{17}$ Critiques such as these originated from the public, the legal profession, journalists, the patients' families and patients and former patients themselves, who in some cases played a central role in the attempts to reform asylums.

http://www.roanoke.com/news/local/salem/salem-council-joins-opposition-tocatawba-hospital-closure/article_1e7e6a64-26e5-578a-87d4-9ddc949fab24.html; http://www.abc.net.au/pm/content/2015/s4279597.htm , accessed 15 February 2016. ${ }^{15}$ E. Haskell (1868) The Trial of Ebenezer Haskell (Philadelphia: Ebenezer Haskell); N. Bly (16 October 1887) 'Inside the Madhouse', New York World.

${ }^{16}$ N. Hervey (1986) ‘Advocacy or Folly: The Alleged Lunatics’ Friend Society, 184563', Medical History, 30, 245-75.

17 I. Dowbiggin (1991) Inheriting Madness: Professionalization and Psychiatric Knowledge in Nineteenth-Century France (Berkeley: University of California Press), ch. 5 . 
Perhaps even more importantly, deinstitutionalisation had its roots in novel community-based services that emerged in the early twentieth century, such as mental hygiene and child guidance clinics. Part of the Progressive Era social reform movements of the late nineteenth and early twentieth centuries, the American mental hygiene movement can be traced in large part to the efforts of former asylum inmate, Clifford Whittingham Beers (1876-1943), who published his asylum experiences in the autobiographical A Mind that Found Itself in 1908. The following year Beers founded the National Committee for Mental Hygiene with philosopher William James (18421910) and psychiatrist Adolf Meyer (1866-1950). Such American endeavours were part of an international mental hygiene movement that was made up of an array of national associations, all of which, despite their distinct characteristics, criticised the conditions in psychiatric hospitals, advocated their improvement and advised treatment and after care outside the hospital. ${ }^{18}$ Placing emphasis on prevention, early treatment and public

${ }^{18}$ M. Thomson (1995) 'Mental Hygiene as an International Movement' in Paul Weindling (ed.) International Health Organisations and Movements, 1918-1939 (Cambridge, Cambridge University Press), pp. 283-304; H. Oosterhuis (2004) 'Between Institutional Psychiatry and Mental Health Care: Social Psychiatry in the Netherlands, 1916-2000', Medical History, 48, 413-28; H. Oosterhuis (2005) 'Outpatient Psychiatry and Mental Health Care in the Twentieth Century. International Perspectives' in M. Gijswijt-Hofstra, H. Oosterhuis, J. Vijselaar and Hugh Freeman (eds.) Psychiatric Cultures Compared: Psychiatry and Mental Health Care in the Twentieth Century: Comparisons and Approaches (Amsterdam: Amsterdam University Press), pp. 248-76; P. Stuart (1997) 'Community Care and the Origins of Psychiatric Social Work', Social Work in Health Care, 25, 25-36. 
education, mental hygiene advanced the idea that psychiatry should go beyond the hospital and engage with society, 'where things have their beginnings', as Meyer put it. ${ }^{19}$ Although not described in terms of mental hygiene or prevention, the free clinics supported by Sigmund Freud (1856-1939) and his followers during the interwar period in Vienna, Berlin and other European cities were also inspired by the desire to provide care in the community to those who needed it most. ${ }^{20}$ Vienna's free clinic, the Ambulatorium, reflected not only the views of Freud himself, which he expressed in 1918 at the Fifth International Congress of the International Psychoanalytical Association in Budapest, that the poor had as much right to treatment as the rich, but also fit into the socially progressive urban renewal underway in 'Red Vienna' and other parts of central Europe. $^{21}$

The child guidance movement which emerged both in North America and Europe in close connection with mental hygiene, provided an example of extra-mural services for children and adolescents: the child guidance clinic. In the US, the child guidance movement can be largely traced to the psychiatrist and criminologist William Healy (1869-1963), who co-founded the Juvenile Psychopathic Institute in Chicago in 1909.

${ }^{19}$ Cited in K. Jones (1999) Taming the Troublesome Child: American Families, Child Guidance, and the Limits of Psychiatric Authority (Cambridge, Mass.: Harvard University Press), p. 53. For similar arguments in the case of France, see J. C. Coffin (2005) "Misery" and "Revolution": The Organisation of French Psychiatry, 19001980' in Gijswijt-Hofstra et al. (eds.) Psychiatric Cultures Compared, pp. 225-47.

${ }^{20}$ E. N. Danto (2005) Freud's Free Clinics: Psychoanalysis and Social Justice, 1918 1938 (New York: Columbia University Press).

${ }^{21}$ Ibid, pp. 1-5. 
${ }^{22}$ Child guidance clinics were initially connected to courts, in order to examine juvenile delinquents, but in the 1920s and 1930s they extended beyond delinquency to treating a variety of childhood and adolescence problems rooted in personality, behaviour and relationships. In other countries, such as the Netherlands and Germany, advocates of social psychiatry, which emphasised the socioeconomic origins of mental illness, encouraged extra-mural care in the form of both preventive programmes and treatment and aftercare for outpatients in facilities such as day hospitals. ${ }^{23}$ In Britain, outpatient

22 Jones, Taming the Troublesome Child, chapter 4; J. Stewart (2006) 'Child Guidance in Interwar Scotland: International Influences and Domestic Concerns', Bulletin of the History of Medicine, 80, 513-39; J. Stewart (2013) Child Guidance in Britain: The Dangerous Age of Childhood (London: Pickering and Chatto), p. 16; D. Thom (1992) 'Wishes, Anxieties, Play and Gestures: Child Guidance in Inter-War Britain' in R. Cooter (ed.) In the Name of the Child: Health and Welfare, 1880-1940 (London: Routledge), pp. 189-212; and B. Evans, R. Shahina and E. Jones (2008) 'Managing the "Unmanageable": Interwar Child Psychiatry at the Maudsley Hospital, London', History of Psychiatry, 19, 454-75.

${ }^{23}$ H.-P. Schmiedebach and S. Priebe (2004) 'Social Psychiatry in Germany in the Twentieth Century: Ideas and Models', Medical History, 48, 449-72; Oosterhuis, 'Between Institutional Psychiatry and Mental Health Care'; R. Dreikurs (1961) 'Early Experiments in Social Psychiatry', International Journal of Social Psychiatry, 7, 14147. 
consultations were introduced in the interwar period and community care for people with mental deficiencies developed as complementary to institutional care. ${ }^{24}$

The Second World War strengthened these discourses of mental hygiene, social psychiatry and community care, as well as precipitating broader public health and welfare measures in many countries. As the leading Australian-British psychiatrist Aubrey Lewis (1900-1975) explained in 1952, four years after the foundation of the National Health Service (NHS): 'The insistent needs and the aspirations of the last war gave a vigorous impetus to social measures in every sphere. This was true of medicine in all its divisions, and notably so in psychiatry which by its nature is a field of social knowledge and practice. ${ }^{25}$ In the US, twelve per cent of all men who volunteered for military duty were rejected on psychiatric grounds, amounting to more than a million people. This figure was six times the rejection figure for the First World War. ${ }^{26}$ Despite these high rejection rates, the American military saw over one million hospital admissions for neuropsychiatric illnesses during the course of the war. As Chief Consultant in Neuropsychiatry for the U.S. Surgeon General, William C. Menninger (1899-1966), stated in 1948: 'Millions of people became really aware, for the first time,

${ }^{24}$ H. Freeman (2005) 'Psychiatry and the State in Britain' in Gijswijt-Hofstra et al. (eds.) Psychiatric Cultures Compared, pp. 116-40; M. Thomson (1998) The Problem of Mental Deficiency: Eugenics, Democracy, and Social Policy in Britain c.1870-1959 (Oxford: Clarendon Press; New York: Oxford University Press), ch. 4.

${ }^{25}$ A. Lewis (1952) 'Forward to M. Jones, Social Psychiatry: A Study of Therapeutic Communities (London: Tavistock Publications, Ltd.), p. vii.

${ }^{26}$ H. Pols and S. Oak (2007) 'War and Military Mental Health: The US Psychiatric Response in the $20^{\text {th }}$ Century, American Journal of Public Health, 97, 2132-42. 
of the effect of environmental stresses on the personality. ${ }^{27}$ Military psychiatry placed an emphasis on prevention (attempting to exclude from service those who were deemed prone to mental illness), adjustment (aiming at the return of the men to battle and thus emphasising the adaptation to the needs and values of the patients' environment) and interpersonal treatment methods (focusing not on traditional army and hospital hierarchies but on responsibility and independence). ${ }^{28}$ Such modifications were notable in the wartime work of some British psychiatrists, including the therapeutic community pioneer Maxwell Jones (1907-1990). As Jones explained: 'War-time needs with the huge volume of psychiatric cases and relative shortage of psychiatrists gave a tremendous stimulus to social methods of treatment in psychiatry. ${ }^{29}$ As the historian Catherine Fussinger describes, this included both flattening the hierarchy between patients and staff and recognising that therapy could occur not merely in a formal

${ }^{27}$ W. C. Menninger (1948) Psychiatry in a Troubled World: Yesterday's War and Today's Challenge (New York: Macmillan), p. xiii.

28 B. Shephard (1999) "Pitiless Psychology": The Role of Prevention in British Military Psychiatry in the Second World War', History of Psychiatry, 10, 491-524; N. Thalassis (2007) 'Soldiers in Psychiatric Therapy: The Case of Northfield Military Hospital 1942-1946', Social History of Medicine, 20, 351-68; D. Healy (2002) The Creation of Psychopharmacology (Cambridge, Mass.: Harvard University Press), p. 131.

${ }^{29}$ M. Jones (1952) Social Psychiatry: A Study of Therapeutic Communities (London: Tavistock Publications, Ltd.), p. viii. 
therapeutic setting, but 'everywhere'. ${ }^{30}$ Wartime disorders, such as combat fatigue, supported the idea that mental illness was caused within a particular social setting and thus could be cured within this environment with early intervention and ambulatory care.

Writing about how soldiers responded psychologically to the stresses of warfare, psychiatrists Roy R. Grinker, Sr. (1900-1993) and John P. Speigel (1911-1991) described how civilians' experiences could similarly trigger mental breakdown. ${ }^{31} \mathrm{War}$ merely amplified phenomena which actually occurred in less fraught environments. ${ }^{32}$

30 C. Fussinger (2011) “"Therapeutic Community”, Psychiatry's Reformers and Antipsychiatrists: Reconsidering Changes in the Field of Psychiatry after World War II', History of Psychiatry, 22, 151-52.

31 R. R. Grinker, Sr. and J. P. Speigel, (1945) Men Under Stress (Philadelphia: Blakiston). Mark Jackson has also discussed the work of Grinker and Speigel.Maybe rephrase: For a discussion on the work of Grinker and Speigel, see M. Jackson (2013) The Age of Stress: Science and the Search for Stability (Oxford: Oxford University Press).

${ }^{32}$ Similarly, the disorder currently associated with combat stress, Post-Traumatic Stress Disorder (PTSD), which emerged specifically in the context of the Vietnam War and entered the third edition of the Diagnostic and Statistical Manual of Mental Disorders in 1980, has more recently been associated with a range of civilian stressors, ranging from sexual abuse to witnessing the 11 September 2001 terrorist attacks on television. See V.V. Wolfe, C. Gentile and D.A. Wolfe (1989) 'The Impact of Sexual Abuse on Children: A PTSD Formulation', Behavior Therapy, 20, 215-28; A. Young (1995) Harmony of Illusions: Inventing Posttraumatic Stress Disorder (Princeton: Princeton 
The experience of the Second World War also reinforced the psychoanalytical view that mental illness existed as part of a continuum with mental health which, in turn, had profound repercussions on how mental illness was understood, diagnosed and treated. ${ }^{33}$ For instance, the continuum model for mental health undermined the recently ascendant biologically-based explanations for mental disorder, which focussed on brain pathology and reinforced the suitability of 'heroic' medical therapies, such as the use of drugs, insulin shock treatment, electro-convulsive shock treatment or lobotomy. A good example of this prior trend is the emergence of post-encephalitic disorder during the 1920s, following an epidemic of encephalitis lethargica (otherwise known as von Economo disease or sleeping sickness). In addition to suffering from movement disorders and Parkinsonism, survivors of this infectious brain disease often suffered from a wide range of mental disturbances, ranging from depression and visual disturbance to sexual precocity and violence, some severe enough to warrant lobotomies. ${ }^{34}$ Given the obvious cause of the post-encephalitic disorder, psychiatrists

University Press); Y. Neria, L. DiGrande and B.G. Adams (2011) 'Posttraumatic Stress Disorder Following the September 11, 2001 Terrorist Attacks: A Review of the Literature Among Highly Exposed Populations', American Psychologist, 66, 429-46; V. Duclos (8 October 2013) 'When Anthropology Meets Science: An Interview with Allan Young', Somatosphere, http://somatosphere.net/2013/10/when-anthropologymeets-science-an-interview-with-allan-young.html, accessed 15 March 2016.

33 G. Grob (1991) From Asylum to Community: Mental Health Policy in Modern America (Princeton, N.J: Princeton University Press), ch. 1.

${ }^{34}$ F. T. Thorpe (1946) 'Prefrontal Leucotomy in Treatment for Post-Encephalitic Conduct Disorder', British Medical Journal, 1, pp. 312-14. 
were encouraged to consider similar brain lesions, dysfunctions or injuries as an explanation for other disorders. ${ }^{35}$ Similarly, the 1906 development of the Wassermann test which identified syphilis in the blood, in tandem with the growing use of malarial therapy in the 1920 s, was hailed both as a solution for general paralysis of the insane (a disease which contributed substantially to asylum death rates), but also as evidence more broadly of the biological roots of mental disorders, the scientific status of psychiatry, and the utility of somatic therapies. ${ }^{36}$ The wartime focus on the mentally pathological environment shifted the focus of many psychiatrists - albeit temporarily away from such biological or, to use a contemporary term, organic causes and, in turn, 'heroic' medical treatments.

${ }^{35}$ E. D. Bond and K. E. Appel (1935) 'Post-Encephalitic Personality Disorders: Their Nature and Treatment', Annals of Surgery, 10, pp. 44-48; A Rafalovich (2001) 'The Conceptual History of Attention-Deficit/Hyperactivity Disorder: Idiocy, Encephalitis, and the Child Deviant, 1877-1929', Deviant Behavior, 22, pp. 93-115; R. Mayes and A. Rafalovich (2007) 'Suffer the Restless Children: The Evolution of ADHD and Paediatric Stimulant use, 1900-1980', History of Psychiatry, 18, pp. 435-57. A recent article has suggested that Adolf Hitler's Parkinsonism may have been as a result of this encephalitis epidemic. K. B. Bhattacharyya (2015) 'Adolf Hitler and his Parkinsonism', Annals of the Indian Academy of Neurology, 18, pp. 387-90.

${ }^{36}$ Although as Gayle Davis observes, psychiatrists' subjective views of their patients and the perceived social profile of the disease mediated the impact of these new diagnostic and treatment methods: G. Davis (2008) 'The Cruel Madness of Love': Sex, Syphilis and Psychiatry in Scotland, 1880-1930 (Amsterdam and New York, Rodopi). 
One of the rationales for such treatments was to ease the burden on mental hospitals, as the work of historians Jack D. Pressman and Mical Raz has demonstrated. ${ }^{37}$ Given that one of the chief objectives of military psychiatrists was to heal psychiatric casualties sufficiently so that they could return to combat, they, too, sought short-term treatments, which, despite their limited therapeutic efficiency, advanced the idea that treatment did not demand the long-term separation of the patients from their environment. ${ }^{38}$ Many influential military psychiatrists, such as William Menninger, urged that the presumed positive benefits of psychotherapy during wartime could and should be applied in civilian psychiatry as well, along with a host of other lessons learned during the War. ${ }^{39}$ As historian Edgar Jones explains, this was quite different from the experience of the First World War, when, for example, the 'network of outpatient clinics, set up by the Ministry of Pensions to treat veterans with shell shock, were closed within a few years in response to financial pressures and doubts about their therapeutic value'. ${ }^{40}$ In the US, the situation was much the same. As the anonymous reviewer of social psychiatrist Thomas A. C. Rennie's (1904-1956) Mental Health in Modern Society (1948) stated, 'all of the lessons we painfully "learned" during the last war [the Second World War] were well known by 1920, were published

37 J.D. Pressman (1998) Last Resort: Psychosurgery and the Limits of Medicine (Cambridge: Cambridge University Press); M. Raz (2013) The Lobotomy Letters: The Making of American Psychosurgery (Rochester: University of Rochester Press).

${ }^{38}$ E. Jones (2004) 'War and the Practice of Psychotherapy: The UK Experience 19391960', Medical History, 48, 496-97.

${ }^{39}$ Menninger, Psychiatry in a Troubled World, pp. 351-62.

${ }^{40}$ Jones, 'War and the Practice of Psychotherapy', 493. 
in psychiatric journals and government reports, and were tragically forgotten' ${ }^{41}$ After the Second World War, in contrast, psychiatrists were eager to implement such 'lessons', including the overarching notion that the mental hospital was not necessarily the best place for the mentally ill to recover. ${ }^{42}$

Mental hygiene, child guidance, free clinics and wartime approaches to psychiatry all help to demonstrate that alternatives to the asylum, in the form of outpatient and community care, were already present in the early twentieth century. It is also important to note that asylum walls had never been totally impermeable: there were always channels of communication between the inside and the outside world, for example in the form of patient outings, temporary leaves and boarding-out, ${ }^{43}$ as well visits from family members, government officials, members of the press and the public. ${ }^{44}$ Although the boundaries between the asylum and the community were not

${ }^{41}$ Anonymous (1948) 'Review of Thomas A. C. Rennie, Mental Health in Modern Society', Journal of the American Medical Association, 138, 249.

${ }^{42}$ Grob, From Asylum to Community, ch. 1.

43 H. Sturdy and W. Parry-Jones (1999) 'Boarding-out Insane Patients: The Significance of the Scottish System 1857-1913' in P. Bartlett and D. Wright (eds.) Outside the Walls of the Asylum: On 'Care and Community' in Modern Britain and Ireland (New Brunswick: Athlone Press), pp. 86-114; M.C. Thifault and I. Perreault (2012) 'The Social Integration of the Mentally Ill in Quebec prior to the Bédard Report of 1962', Canadian Bulletin of Medical History, 29, 125-50.

44 For example, D. MacKinnon (2009) 'Amusements are provided': Asylum Entertainment and Recreation in Australia and New Zealand c.1860-c.1945' in G. 
easily dissolved - as shown by the difficulties in the implementation of the formal, postwar deinstitutionalisation efforts - asylums were never completely isolated from the broader environment in which they were situated.

\section{Origins of Deinstitutionalisation}

Escalating concerns about mental health following the Second World War forced both psychiatrists and politicians to consider alternatives to hospitalisation. While mental hospitals initially remained central to the provision of mental health care and were reorganised in an attempt to improve services and to take advantage of new treatments, more emphasis was placed on the ambulant sector and the expansion of outpatient services. ${ }^{45}$ As a 1949 article in the American journal Public Health Reports indicated, there was 'widespread interest throughout the country in community mental health clinics' that would 'develop adequate mental health programs, particularly in the fields

Mooney and J. Reinarz (eds.) Permeable Walls: Historical Perspectives on Hospital and Asylum Visiting (Amsterdam; New York: Rodopi), pp. 267-88.

${ }^{45}$ Stewart, "The dangerous age of childhood"'; Jones, Taming the Troublesome Child, pp. 206, 210 224; M. Gijswijt-Hofstra (2005) 'Within and Outside the Walls of the Asylum. Caring for the Dutch Mentally Ill, 1884-2000' in Gijswijt-Hofstra et al. (eds.) Psychiatric Cultures Compared, pp. 35-72; Oosterhuis, 'Outpatient Psychiatry and Mental Health Care in the Twentieth Century'; L. de Goei (1998) 'Psychiatry and Society: The Dutch Mental Hygiene Movement 1924-1960’ in M. Gijswijt-Hofstra and R. Porter (eds.) Cultures of Psychiatry and Mental Health Care in Postwar Britain and the Netherlands (Amsterdam: Rodopi), pp. 61-78; Thomson, The Problem of Mental Deficiency, ch. 4. 
of early prevention and treatment'. ${ }^{46}$ Such an approach was also reflected in the way in which the newly founded World Health Association (WHO) grounded its mental health care reform policy on prevention and outpatient care. ${ }^{47}$

A panoply of explanations help to explain why deinstitutionalisation happened, ranging from developments within psychiatry itself to broader political, philosophical and economic changes. The Second World War had put a spotlight on mental illness, but just what kind of psychiatry was envisioned to treat it? Post-war psychiatry was nothing if it was not diverse. While biological psychiatrists had access to new drugs, such as methylphenidate and chlorpromazine, along with other 'heroic' remedies, dynamic psychiatry was also entering its heyday, especially in the US, where being trained in psychoanalysis was a necessary condition of employment in many clinical

${ }^{46}$ E. Davens and P. Lemkau (1949) 'Birth of a Community Mental Health Clinic', Public Health Reports, 27, 657.

47 S. Sturdy, R. Freeman and J. Smith-Merry (2013) 'Making Knowledge for International Policy: WHO Europe and Mental Health Policy, 1970-2008', Social History of Medicine, 26, 532-54. WHO's focus on prevention in the post-war period reflects its concerns today about the prevalence of mental disorders globally. Stating that depression will be the world's leading cause of disease by 2030, representing thirteen per cent of global disease, WHO mentions prevention in its list of strategies to deal with the problem, but it appears to be less of a priority than in times past. WHO, 'Global Burden of Mental Disorders and the Need for a Comprehensive, Coordinated Response from Health and Social Sectors at the Country Level', Executive Board, $130^{\text {th }}$ $\begin{array}{llll}\text { Session, } & \text { Provisional } & \text { Agenda }\end{array}$ http://apps.who.int/gb/ebwha/pdf_files/EB130/B130_9-en.pdf, accessed 3 April 2016. 
and academic settings. At the same time, social psychiatry was highly influential, with many of the presidents of national psychiatric associations, such as the American Psychiatric Association, supporting its preventive tenets and calling for public mental health, and many politicians intrigued by its approach. ${ }^{48}$ The launch of the International Journal of Social Psychiatry in 1954, which was edited by the British psychiatrist Joshua Bierer (1901-1984) and was followed by the launch of Social Psychiatry in 1966, also indicates its emergence as an important strand within psychiatry. Moreover, within these relatively distinct disciplines there was both diversity and overlap. Some psychoanalysts were willing to use drugs, such as Ritalin, to facilitate psychotherapy, and some biological psychiatrists, including Leon Eisenberg, who conducted some of the first clinical trials of Ritalin, were also committed to the ideas of social psychiatry. ${ }^{49}$ Some psychiatrists who had hitherto championed physical therapies, such as Rudolf Freudenberg, one of the pioneers of insulin coma therapy, subsequently embraced

${ }^{48}$ See W.C. Menninger (1949) 'Presidential Address', American Journal of Psychiatry, 106, 2-12; K.B. Appel (1954) 'Presidential Address: The Present Challenge of Psychiatry', American Journal of Psychiatry, 111, 1-12; W.E. Barton (1962) 'Presidential Address: Psychiatry in Transition', American Journal of Psychiatry, 119, 1-15; C. H. H. Branch (1963) 'Presidential Address: Preparedness for Progress', American Journal of Psychiatry, 120, 1-11.

${ }^{49}$ L. Eisenberg (1962) 'Preventive Psychiatry', Annual Review of Medicine, 13, 34360. 
social approaches and interventions.$^{50}$ Psychotherapy may have been synonymous with Freudianism to most of the lay public, but varieties ranging from those developed by Carl Jung (1875-1961) to Wilhelm Reich (1897-1957) also attracted adherents. Equally, biological psychiatry encompassed everything from shock therapies and psychosurgery to experiments in Saskatchewan to understand the therapeutic uses of LSD. ${ }^{51}$ Even social psychiatry existed on a continuum, stretching from the relatively cautious approach of academic researchers (many of whom were social scientists and not psychiatrists) to exponents of 'radical psychiatry'. ${ }^{52}$ These approaches to psychiatry might have been remarkably different, but they all shared one thing in common: the hopes and promises they offered all contributed to deinstitutionalisation, though to differing degrees and in different ways.

One of the defining features of dynamic psychiatry was that mental distress could affect anyone. The corollary to this was that many more people outside the asylum needed the attention of mental health care professionals. But how would dynamic psychiatrists, especially those conducting time-intensive and expensive psychoanalysis, be able to treat the countless people believed to be in need of treatment? This issue, rather than the efficacy of psychoanalysis, was the one that troubled dynamic

${ }^{50}$ T. Becker and D. Bennett (2000) 'Rudolf Karl Freudenberg — from Pioneer of Insulin Treatment to Pioneering Social Psychiatrist', History of Psychiatry, 11, 189211.

${ }^{51}$ E. Dyck (2008) Psychedelic Psychiatry: LSD from Clinic to Campus (Baltimore: The Johns Hopkins University Press).

52 L. Richert (2013) “"Therapy Means Political Change, Not Just Peanut Butter”: American Radical Psychiatry, 1968-1975', Social History of Medicine, 27, 104-21. 
psychiatrists during the post-war period. One solution was to open up psychoanalysis to lay analysts (those without a medical degree), which had been something Freud welcomed and written about in $1926 .{ }^{53}$ Although some psychiatrists welcomed this, stating that social workers, psychologists and even priests could perform such a function, others argued that all psychoanalysts should have a medical degree. ${ }^{54}$ Their solution was to recruit more psychiatrists, which had long been a challenge in many jurisdictions and dominated the concerns of many psychiatric associations. Regardless of who conducted psychoanalysis, the predominance of dynamic psychiatry during the post-war period contributed to the re-orientation of the psychiatric gaze from chronic and severe patients likely to be found in institutions to outpatients with acute and mild mental health problems.

Most social psychiatrists, in contrast, were not at all confident that psychoanalysis had the efficiency nor the efficacy to cope with the tide of the mentally unwell, and believed that prevention was neglected in favour of treatment. ${ }^{55}$ Social psychiatrists believed that mental health problems stemmed from the patient's environment, often citing socioeconomic factors such as poverty, overcrowding, violence, racism and

${ }^{53}$ S. Freud (1990) The Question of Lay Analysis (New York: W. W. Norton).

${ }^{54}$ G.J. Sarwer-Foner (1986) 'On the Differences in the Historical Development of Psychoanalysis in the United States and Canada', Canadian Journal of Psychiatry, 31, 227-32.

${ }^{55}$ L. Eisenberg (1966) 'Discussion of Dr. Solnit's “Who Deserves Child Psychiatry: A Study in Priorities"', Journal of the American Association of Child Psychiatry, 5, 1723. 
social exclusion. ${ }^{56}$ As such, it was the community, not the hospital, that had to be the basis for both psychiatric treatment and, more importantly, prevention. Within this context more outpatient services were needed, such as the day hospitals first founded during the late 1940s by the Scot Ewen Cameron (1901-1967) in Canada and Joshua Bierer in the UK, occupational mental health centres, community mental health centres, therapeutic communities, specialised services for children and the elderly, follow-up services and transitional living facilities. ${ }^{57}$ In the era of deinstitutionalisation, many of these community services were initially sited within or developed out of psychiatric

${ }^{56}$ See R.E.L. Faris and H.W. Dunham (1939) Mental Disorder in Urban Areas (Chicago: University of Chicago Press); A.B. Hollingshead and F.C. Redlich (1958) Social Class and Mental Illness: A Community Study (New York: John Wiley); L. Srole, T.S. Langer, S.T. Michael, M.K. Opler, T.A.C. Rennie, Mental Health in the Metropolis: The Midtown Manhattan Study, Volume 1 (New York: McGraw Hill).

${ }^{57}$ E. Shorter (2005) A Historical Dictionary of Psychiatry (Oxford: Oxford University Press), p. 59; A. Roberts and L. Kurtz (2015) 'Historical Perspectives on the Care and Treatment of the Mentally Ill', The Journal of Sociology \& Social Welfare, 14, 75-94. Various publications on day hospitals can be found in the International Journal of Social Psychiatry. See for example R.A. Stewart (1956) 'The Institute of Social Psychiatry', International Journal of Social Psychiatry, 2, 214-19; M. Axel (1959) 'Treatment of Schizophrenia in a Day Hospital: Preliminary Observations on an Eclectic Approach', International Journal of Social Psychiatry, 5, 174-81 and J. Bierer (1961) 'Day Hospitals: Further Developments', International Journal of Social Psychiatry, 7, 148-51. 
hospitals, as hospitals forged new links with external organisations. ${ }^{58}$ However, community mental health was meant to replace institutionalisation, both in terms of providing care in the community, but also by initiating the preventive strategies that would eventually see a reduction in the rates of mental illness and, therefore, the need for such facilities. Although demonstrating preventive psychiatry in practice was much more difficult than describing it in theory, it was compelling enough to convince many psychiatrists, politicians and activists that institutions could become a thing of the past. $^{59}$

Finally, biological psychiatry's main contribution to deinstitutionalisation was the introduction of antipsychotic drugs in the 1950s. Drugs, such as chlorpromazine,

${ }^{58}$ D.F. Early (1963) 'The Industrial Therapy Organisation (Bristol): A Development of Work in Hospital', The Lancet, 281:7278, 435-36; V. Long (2013) 'Rethinking Postwar Mental Health Care: Industrial Therapy and the Chronic Mental Patient in Britain', Social History of Medicine, 26, 738-58. On precedents for this trend, see S. Soanes (2009) 'Reforming Asylums, Reforming Public Attitudes: J.R. Lord and Montagu Lomax's Representations of Mental Hospitals and the Community', Family and Community History, 12, 117-29.

${ }^{59}$ For a scathing indictment of social psychiatry in the U.S., see E.F. Torrey (2013) American Psychosis: How the Federal Government Destroyed the Mental Illness Treatment System (New York: Oxford University Press). Others have been more sympathetic: D. Blazer (2005) The Age of Melancholy: 'Major Depression' and its Social Origins (New York: Routledge); H. Pols (2007) 'August Hollingshead and Frederick Redlich: Poverty, Socioeconomic Status, and Mental Illness', American Journal of Public Health, 97, 1755. 
sparked what has been called a 'psycho-pharmaceutical revolution', which enabled the clinical improvement of more patients and their discharge from mental hospitals, and made treating people with severe mental illnesses in the community possible. ${ }^{60}$ Profiting from the antibiotics that proliferated after the Second World War, pharmaceutical companies sought similar magic bullets for mental illness and synthesised an array of new products, as the advertisements in psychiatry journals highlight. The new drugs however did not initially aim at overthrowing the asylum; they were firstly used in institutions to treat inpatients, regulating behaviour, facilitating hospital routine and even enabling psychoanalysis. ${ }^{61}$ In some countries the use of antipsychotic medication coincided with the rise of psychiatric inpatients between the 1950s and the 1970s. In addition, open-door policies, community psychiatry and hospital closure had started before the advent of the first efficient drugs. ${ }^{62}$ Therefore,

${ }^{60}$ W. Gronfein (1985) 'Psychotropic Drugs and the Origins of Deinstitutionalization', Social Problems, 32, 437-54.

${ }^{61}$ Dyck, Psychedelic Psychiatry, pp. 30-31. See also M.A. Ramos (2013) 'Drugs in Context: A Historical Perspective on Theories of Psychopharmaceutical Efficacy', Journal of Nervous and Mental Disorders, 201, 926-33.

62 S.L. Starks and J.T. Braslow (2005) 'The Making of Contemporary American Psychiatry, Part 1: Patients, Treatments, and Therapeutic Rationales before and after World War II', History of Psychology, 8, 176-93; Healy, The Creation of Psychopharmacology, pp. 62, 129, 134; D. Pilgrim and A. Rogers (1999) A Sociology of Mental Health and Illness (Buckingham: Open University Press), ch. 8, table 8.1; L. Clarke (1993) 'The Opening of Doors in British Mental Hospitals in the 1950s', History of Psychiatry, 4, 527-51. 
although psychiatric medication contributed to the move to the community, it was not its sole or main cause and had to be complemented with social treatments, in order to lead to the reintegration of patients in their social environment and to a deinstitutionalised mental health system. ${ }^{63}$ What the new drugs, along with enthusiasm about dynamic and social psychiatry, did, however, was to boost the confidence of psychiatrists that they were not only fully capable of coping with the tide of mental illness facing western society, but also convincing governments and policy makers to provide political and financial support for their ambitions. In the case of patients coping with severe, chronic mental illness who would have previously been institutionalised, such hopes, as we shall see, would not last. But in the case of outpatients with mild or moderate symptoms that responded well to drugs and/or psychotherapy, psychiatrists could claim success. The degree to which these more commonplace symptoms - and the new disorders that enveloped them - were the creation of pharmaceutical companies and ambitious psychiatrists, however, remains a highly contentious issue. ${ }^{64}$

Apart from the combined dynamic, social and biological strands of mental health care, deinstitutionalisation was linked to economic, cultural and political developments

${ }^{63}$ V. Long (2012) “'Often There Is a Good Deal to be Done, But Socially Rather Than Medically": The Psychiatric Social Worker as Social Therapist, 1945-70', Medical History, 55, 223-39.

${ }^{64}$ See D. Healy (1997) The Antidepressant Era (Cambridge: Harvard University Press); D. Herzberg (2009) Happy Pills in America: From Miltown to Prozac (Baltimore: The Johns Hopkins University Press); A. Tone (2009) The Age of Anxiety: A History of America's Turbulent Affair with Tranquilizers (New York: Basic Books); M. Smith (2012) Hyperactive: The Controversial History of ADHD (London: Reaktion). 
of the late twentieth century. The best known articulation of the socio-economic understanding of deinstitutionalisation has been Andrew Scull's 1977 book Decarceration, which argued that the implementation of alternatives to institutionalisation was triggered by increasing financial pressures on the state during the 1960s and 1970s. He saw deinstitutionalisation as a 'shift in social control styles and practices' that was 'dependent upon and a reflection of more extensive and deepseated changes in the social organization of advanced capitalist societies' ${ }^{65}$ Contemporary articles indicating the potential savings offered by deinstitutionalisation reinforce Scull's argument. ${ }^{66}$ Others have pointed out, however, that the move to community care started in the 1950 s and thus predated the economic strains ${ }^{67}$ that heightened in the $1980 \mathrm{~s}$ - the 'decade of scarcity'. ${ }^{68}$ Indeed, Richard Warner argues that it was the demands of the post-war labour market which fuelled deinstitutionalisation, providing employment opportunities for psychiatric patients which in turn fostered the development of occupational rehabilitation services. $\mathrm{He}$ contends that countries which experienced higher unemployment rates after the Second World War, such as Italy, embraced psychiatric rehabilitation at a later stage, while

${ }^{65}$ A. Scull (1977) Decarceration: Community Treatment and the Deviant. A Radical View (Englewood Cliffs, New Jersey: Prentice-Hall), p. 152.

${ }^{66}$ J.G. Murphy and W.E. Datel (1976) 'A Cost-Benefit Analysis of Community Versus Institutional Living', Hospital and Community Psychiatry, 27, 165-70.

67 J. Busfield (1986) Managing Madness: Changing Ideas and Practice (London: Hutchinson).

${ }^{68}$ Roberts and Kurtz, 'Historical Perspectives on the Care and Treatment of the Mentally Ill'. 
rising unemployment levels, as in Britain from the 1970s onwards, served to curtail the development of psychiatric rehabilitation and community services. ${ }^{69}$ In any case it cannot be denied that the conviction that community services would be inexpensive in comparison to residential ones provided an important motive to administrations for moving mental health care to the community.

The ideological and social climate of the 1960s and 1970s also provided arguments for deinstitutionalisation. Although, as already noted, the efficiency, efficacy and humanity of mental hospitals had been challenged since the nineteenth century, criticisms peaked during the decades following the Second World War. In 1959, the British psychiatrist Russell Barton (1924-2002) proposed the term 'institutional neurosis' to describe the effects of institutional life on the patients, such as apathy and lack of individuality. ${ }^{70}$ Two years later the Canadian-American sociologist Ervin Goffman (1922-1982), who had worked for the National Institute of Mental Health, characterised psychiatric hospitals as one type of 'total institutions', which cut off their inmates from the wider society, restricting their self-determination, autonomy and freedom of action. ${ }^{71} \cdot{ }^{72}$

Critiques such as these were accompanied by a host of others, which would attack institutionalisation from multiples perspectives. Some, like that of Burton, were from

${ }^{69}$ R. Warner (2004) Recovery from Schizophrenia: Psychiatry and the Political Economy (Hove: Routledge) pp. 80-101.

${ }^{70}$ R. Barton (1959) Institutional Neurosis (Bristol: Wright).

${ }^{71}$ E. Goffman (1961) Asylums: Essays on the Social Situation of Mental Patients and Other Inmates (York: Anchor Books). 
within psychiatry itself. In 1960, for instance, the Scot R. D. Laing (1927-1989) questioned why the experiences of the psychotic could not be interpreted as valid, thus questioning why such people were labelled as mentally ill. ${ }^{73}$ Laing, who had worked at Gartnavel Royal Medical Hospital in Glasgow in the early 1950s, became convinced that the power dynamic between psychiatrists and patients in conventional mental hospitals militated against therapeutic goals, explaining to documentary maker Peter Robinson in 1971 that 'if you are interviewing a patient in a mental hospital ward and you have a key in your pocket to get out and the patient hasn't, the gulf in power, in position, is enormous. ${ }^{74}$ The South African psychiatrist David Cooper (1931-1986), who worked with Laing at Kingsley Hall in London and, with him and others founded the Philadelphia Association in 1965, provided a Marxist critique of the legitimacy of mental illness. He would coin the term 'anti-psychiatry', which was frequently applied to critics of psychiatry, often despite their protestations. ${ }^{75}$ But psychiatry's critics did not have to emanate from the left. The libertarian American psychiatrist Thomas Szasz (1920-2012), for instance, was particularly critical of involuntary commitment, arguing

${ }^{73}$ R.D. Laing (1960) The Divided Self: An Existential Study in Sanity and Madness (Harmondsworth: Penguin); G. Miller (2004) R.D. Laing (Edinburgh: Edinburgh University Press); A. Beveridge (2011) Portrait of the Psychiatrist as a Young Man: The Early Writing and World of R.D. Laing, 1927-1960 (Oxford: Oxford University Press); C. McGeachan (2014) “"The World is Full of Big Bad Wolves”: Investigating the Therapeutic Spaces of R.D. Laing and Aaron Esterton', History of Psychiatry, 25, 283-98

\footnotetext{
74 ‘Asylum’ (1971), documentary directed by P. Robinson.

${ }^{75}$ D. Cooper (1967) Psychiatry and Anti-Psychiatry (London: Tavistock).
} 
in the falsificationist style of the philosopher Karl Popper (1902-1994) - who also had his misgivings about psychiatry - that most mental illnesses were merely metaphorical, since they could not be attributed to brain pathology. ${ }^{76}$

Literary and historically-informed reactions to institutionalisation emerged as well. In 1962, after working at a Veterans' Hospital in Oregon, Ken Kesey (1935-2001) published One Flew Over the Cuckoo's Nest, which also raised questions about psychiatric institutions and 'heroic' therapies. ${ }^{77}$ The book would later become an Academy Award-winning film in 1975. Historians, philosophers and sociologists, such as Michel Foucault (1927-1984), David Rothman and Andrew Scull, also began critiquing the asylum by examining its history, though revisionist accounts soon followed (or in the case of Grob's The State and the Mentally Ill, coincided) ${ }^{78}$ Mental patients also began voicing their own opinions about institutionalisation, as the civil rights movements of the post-war period gathered momentum. By the late 1960s, the

76 T. Szasz (1961) The Myth of Mental Illness (New York: Harper and Row).

${ }^{77}$ K. Kesey (1962) One Flew Over the Cuckoo's Nest (New York: Viking).

${ }^{78}$ M. Foucault (1961) Histoire de la Folie à l’ Âge Classique: Folie et Déraison (Paris: Plon); D. Rothman (1971) The Discovery of the Asylum: Social Order and Disorder in the New Republic (Boston: Little, Brown); A. Scull (1979) Museums of Madness: The Social Organization of Insanity in Nineteenth-Century England (New York: St. Martin's Press); G.N. Grob (1966) The State and the Mentally Ill: A History of Worcester State Hospital in Massachusetts, 1830-1920 (Chapel Hill: University of North Carolina Press); N. Tomes (1984) The Art of Asylum-Keeping: Thomas Story Kirkbride and the Origins of American Psychiatry (Philadelphia: University of Pennsylvania Press). 
emergent Psychiatric Survivors' Movement was depicting mental patients as an oppressed minority, with mental hospitals depicted as repressive institutions that violated their human and civil rights, and psychiatry as an inhuman, authoritative or false science. Former patient Judi Chamberlain (1944-2010), who had been involuntarily confined to an asylum in New York during the mid-1960s, would articulate such concerns in On Our Own: Patient-Controlled Alternatives to the Mental Health System. ${ }^{79}$ While the different social movements, organisations and individuals who contested conventional psychiatric practice frequently clashed, their interactions nevertheless served to construct and power a field of psychiatric contention. ${ }^{80}$ Despite their disparity, all such critics challenged madness as a medical category, proposed social models of mental distress and suggested various degrees of reform, from the transformation to the demise of psychiatric hospitals. They also, perhaps unwittingly in some cases, fuelled the desire of administrators to shut down institutions for the sake of reducing costs: if mental institutions were inhuman, oppressive and inefficient, there was no reason to spend so much money to keep them operating. ${ }^{81}$ Pushed to the side amidst the ideology and rhetoric, however, was the issue of what would happen to the patients (both current and future) who would no longer have access to such institutions.

${ }^{79}$ J. Chamberlain (1978) On Our Own: Patient-Controlled Alternatives to the Mental Health System (New York: Haworth Press).

${ }^{80}$ N. Crossley (2006) Contesting Psychiatry: Social Movements in Mental Health (Abingdon: Routledge).

${ }^{81}$ N. Dain (1989) 'Critics and Dissenters: Reflections on "Antipsychiatry" in the United States', Journal of the History of the Behavioral Sciences, 25, 3-25. 


\section{Different paths and paces}

As suggested above, one could argue that deinstitutionalisation during the post-war period was continuing and building on practices already in place for at least half a century. ${ }^{82}$ These continuities with the pre-war period notwithstanding, the scale and ideological importance of deinstitutionalisation following the Second World War situate it more suitably as a post-war phenomenon, which accelerated, generalised and intensified during the 1970s, 1980s and 1990s. Deinstitutionalisation was in no case a homogenous process, but progressed at different paces and to different degrees in different countries and among different hospital populations. With respect to the latter, it was resisted longer and started later in institutions that cared for psychogeriatric patients, the mentally handicapped, those suffering from Down's syndrome, brain damage or other organic disabilities. ${ }^{83}$ By and large, however, the greatest discrepancies in how deinstitutionalisation materialised occurred in different countries, not least with respect to when the process began. As with many post-war developments in mental health, the place where deinstitutionalisation got its start was the United States.

Although the American community mental health movement began in the 1940s, initiating a first wave of 'passive' deinstitutionalisation through the implementation of alternative services of mental health, it took time for the momentum behind

${ }^{82}$ Barham, Closing the Asylum; D. MacKinnon and C. Coleborne (2003) 'Introduction: Deinstitutionalisation in Australia and New Zealand', Health and History, 5:2, 1-16; Thifault and Perreault, 'The Social Integration of the Mentally Ill in Quebec'.

${ }^{83}$ J. Trent (1999) Inventing the Feeble Mind: A History of Mental Retardation in the United States, 1840-1990 (Berkeley: University of California Press), pp. 241-42, 25556, 262. 
deinstitutionalisation to build and for widespread and concerted action to occur. ${ }^{84}$ Asylum populations continued to grow during the first decade following the end of the Second World War, rising from nearly 500,000 in 1946 to 559,000 in 1955 . This was despite the emergence of a host of therapies, ranging from lobotomies and the first antipsychotic drugs to psychotherapy and therapeutic communities, believed to be capable of helping the mentally ill return to their homes. Other figures, however, reveal that a transformation was occurring. The asylum population, for example, was getting much older, a trend that had begun in the 1940s. By 1958, a third of asylum patients were over sixty-five years old; elderly patients also constituted an increasingly high percentage of first admissions. ${ }^{85}$ The mental hospital was also ceasing to be where most psychiatrists worked, a profound shift from earlier eras. Whereas half of American psychiatrists worked in asylums in 1947, only sixteen per cent did in 1958, reflecting not only the decreasing reliance on institutional psychiatric care, but also proliferation of psychotherapeutic and, to a lesser extent, research opportunities for American psychiatrists, after the foundation of the National Institutes of Mental Health (NIMH) by the National Mental Health Act in $1949 .{ }^{86}$ As the chapter on deinstitutionalisation in Canada indicates, other mental health professionals, including psychiatric nurses and social workers, were also affected by such changes.

${ }^{84}$ Roberts and Kurtz, 'Historical Perspectives on the Care and Treatment of the Mentally Ill'.

${ }^{85}$ Grob, From Asylum to Community, p. 159.

${ }^{86}$ N. Hale (1995) The Rise and Crisis of Psychoanalysis in the United States: Freud and the Americans, 1917-1985 (New York: Oxford University Press), p. 339. 
By the 1960s, these changes were being reflected in the number of patients residing in mental hospitals. The pace varied among different states, but was generally slow between 1955 and 1965, accelerating between the late 1960s and 1970s, when deinstitutionalisation entered a more radical phase, not the least because of the expansion of the welfare state, that offered adequate economic support to residential alternatives. ${ }^{87}$ Between 1966 and 1975, for instance, the American asylum population decreased by 250,000 , reaching a total of 115,000 in $1990 .{ }^{88}$ Making these precipitous drops more striking is that they occurred at a time when the US population was increasing rapidly, buoyed not least by the emergence of the baby boom generation, the largest cohort in American history.

Although Italy might be somewhat of an exception, in most instances, deinstitutionalisation tended to be a gradual process that required considerable political momentum. A variety of American voices, including journalist and historian Albert

${ }^{87}$ J.P. Morrissey (1982) 'Deinstitutionalizing the Mentally Ill: Process, Outcomes, and New Directions' in W.R. Gove (ed.) Deviance and Mental Illness (Beverly Hills: Sage Publications), pp. 147-76; J.P. Morrissey (1989) 'The Changing Role of the Public Mental Hospital' in D.A. Rochefort (ed.) Handbook on Mental Health Policy in the United States (Westport, Conn.: Greenwood Publishing Group), pp. 311-38; D. Mechanic and D.A. Rochefort (1990) 'Deinstitutionalization: An Appraisal of Reform', Annual Review of Sociology, 16, 301-27.

${ }^{88}$ R. Miller, A.N. Ponce, and K.S. Thompson (2011), 'Deinstitutionalization and the Community Mental Health Movement (1954-1976) in M. Rowe, M.Lawless, K. Thompson and L. Davidson (eds.), Classics of Community Psychiatry: Fifty Years of Public Mental Health Outside the Hospital (Oxford: Oxford University Press), p. 12. 
Deutsch (1905-1961) and journalist and mental health crusader Mike Gorman (19131989), had been criticising the state mental hospital system since the 1940s. Both Deutsch's The Shame of the States and Gorman's Oklahoma Attacks its Snake Pits, a pamphlet written for the National Mental Health Foundation later republished in Reader's Digest, exposed the terrible conditions, including chronic overcrowding, in state mental hospitals, generating widespread outrage. ${ }^{89}$ One response to such concern in 1949 was the commissioning of a comprehensive study of mental health care in the then forty-eight states which recommended not only that overcrowding be address, but also that many more out-patient clinics be established. ${ }^{90}$ Prevention of mental illness and promotion of mental health was also stated as a state responsibility. ${ }^{91}$

But, although a small number of states, including Minnesota and New York, began community mental health reform during the 1950s, and despite the formation of the National Institutes of Mental Health in 1949, presidential involvement was ultimately required to spur the federal government to get involved actively in the process of deinstitutionalisation. ${ }^{92}$ In an address to Congress by John F. Kennedy

${ }^{89}$ A. Deutsch (1948) The Shame of the States (New York: Harcourt, Brace); M. Gorman (1948) Oklahoma Attacks its Snake Pits (Philadelphia: National Mental Health Foundation).

${ }^{90}$ The Council of State Governments (1950) The Mental Health Programs of the FortyEight States (Chicago: The Council of State Governments).

${ }^{91}$ Ibid, p. 5.

${ }^{92}$ American States began taking on the responsibility for caring for the indigent insane during the mid-to late nineteenth century, following the campaigning of Dorothea Dix (1802-1887), which ushered in the construction of the first generation of state mental 
(1917-1963) in 1963, the president lamented that 600,000 patients were 'confined and compressed' in state mental hospitals, along with 200,000 more in facilities for 'mental retardation'. ${ }^{93}$ Kennedy, whose sister Rosemary Kennedy (1918-2005) had been subject to a botched lobotomy at the hands of the psychosurgery enthusiast Walter Freeman (1895-1972) in 1941, might have had personal reasons for his interest in mental health, ${ }^{94}$ but the sheer financial cost of institutionalisation also played a major role in fomenting a change. ${ }^{95}$ Kennedy calculated that $\$ 2.4$ billion was being spent annually on mental hospitals, adding that this figure amounted to ' $\$ 4$ a day - too little to do much good for the individual, but too much if measured in terms of efficient use of our mental health dollars' ${ }^{96}$ Moreover, despite the fact that the American Psychiatric Association (APA) had established new standards for the quality of care and treatment in mental hospitals - essentially ensuring that they would be on par with that of general hospitals - the perception was that most institutions remained 'antiquated' and

hospitals. G.N. Grob (1983) Madness in American Society, 1875-1940 (Princeton: Princeton University Press).

93 J.F. Kennedy (1963) 'Special Message to Congress on Mental Illness and Mental Retardation', 5 February, 1963, http://www.presidency.ucsb.edu/ws/?pid=9546.

94 E. Shorter (2000) The Kennedy Family and the Story of Mental Retardation (Philadelphia: Temple University Press).

${ }^{95}$ B. Robb (1967) Sans Everything: A Case to Answer (London: Nelson); A. Scull (2011) 'The Mental Health Sector and the Social Sciences in Post-World War II USA. Part 2: The Impact of Federal Research Funding and the Drugs Revolutions', History of Psychiatry, 22, 268-84, 271.

${ }^{96}$ Kennedy, 'Message to Congress'. 
'overcrowded'. ${ }^{97}$ Kennedy's speech helped to pass the Community Mental Health Centers Construction Act in October 1963, which paid for the building of the community mental health centres meant to replace mental hospitals; his assassination later that year helped pave the way for an amendment which provided funding to staff these centres.

Deinstitutionalisation was often a similarly gradual - yet often convoluted process in other countries. In England and Wales, community care was included in mental health policy since the 1930s; under the 1930 Mental Treatment Act outpatient and voluntary treatment was allowed and encouraged. ${ }^{98}$ The changes were codified in the 1959 Mental Health Act and mental hospitals' population started to diminish in the mid-1950s, while community mental health centres were founded in the $1970 \mathrm{~s} .{ }^{99}$ At the same time accusations of abuse and neglect in British psychiatric hospitals led to a string of government inquiries, which damaged the reputations of these institutions, ${ }^{100}$

${ }^{97}$ Ibid; Grob, From Asylum to Community, p. 80.

${ }^{98}$ Freeman, 'Psychiatry and the State in Britain'.

${ }^{99}$ G.W. Brown, M. Bone, B. Dalison and J.K. Wing (1966) Schizophrenia and Social Care (London: Oxford University Press); J.K. Wing and G.W. Brown (1970) Institutionalism and Schizophrenia: A Comparative Study of Three Mental Hospitals, 1960-1968 (Cambridge: Cambridge University Press); Pilgrim and Rogers, A Sociology of Mental Health and Illness, ch. 8.

${ }^{100}$ See, for example, National Health Service (1969) Report of the Committee of Inquiry into Allegations of Ill-Treatment of Patients and other Irregularities at Ely Hospital, Cardiff, Cmnd. 3975 (London: HMSO); National Health Service (1972) Report of the Committee of Inquiry into Whittingham Hospital, Cmnd. 4861 (London: HMSO). 
while concerns about mental hospitals was expressed during the 1960s by then Minister of Health, Enoch Powell (1912-1998), and by reformer Barbara Robb in her book Sans Everything, which detailed the conditions of the back wards. But, as in the US, momentum behind the transformation from institutional care to 'care in the community' was slow to build: the policy of 'Care in the Community' did not get fully adopted until the 1983 Mental Health Act. ${ }^{101}$ The government's decision to devolve responsibility for the design, funding and delivery of community-based services to local authorities, while failing to compel the establishment of such services or provide the funds necessary to do so, slowed the pace of deinstitutionalisation in England and Wales. ${ }^{102}$ The first mental hospital closed down only in 1985, during which time during which time mental hospitals continued to receive most of the state resources allocated to mental health. Moreover, while the number of psychiatric hospital beds decreased, the number of small hospitals and amount of short-term hospital treatment increased. ${ }^{103}$

${ }^{101}$ A. Scull (2004) 'The Insanity of Place', History of Psychiatry, 15, 417-36, 430; C. Hilton (2007) 'Changes between the 1959 and 1983 Mental Health Acts (England and Wales), with Particular Reference to Consent for Electroconvulsive Therapy', History of Psychiatry, 18, 217-29.

${ }^{102}$ K. Jones (1993) Asylums and After: A Revised History of the Mental Health Service: From the Early 18 ${ }^{\text {th }}$ Century to the 1990s (London: Athlone), pp. 181-96; T. Butler (1993) Changing Mental Health Services: The Politics and Policy (London: Chapman and Hall), pp. 36-51.

${ }^{103}$ Mechanic and Rochefort, 'Deinstitutionalization: An Appraisal of Reform'; Pilgrim and Rogers, A Sociology of Mental Health and Illness, ch. 8. 
The passing of the 1960 Mental Health (Scotland) Act, which largely mirrored English legislation, initially suggested that Scotland would follow England's path towards psychiatric deinstitutionalisation in the 1960s. ${ }^{104}$ Indeed Scotland was home to a number of progressive and even radical Scottish psychiatrists, ranging from George Morrison Carstairs (1916-1991) to R.D. Laing, ${ }^{105}$ and had witnessed experiments to transform psychiatric care. Dingleton Hospital, located in Melrose, in the Scottish Borders, for instance, pioneered an open door policy in 1945 and was developed as a therapeutic community by Maxwell Jones in the early 1960s. ${ }^{106}$ However, the Department of Heath for Scotland's insistence that psychiatric hospitals would continue to function for many years proved to be a self-fulfilling prophecy, and proposals to close Scottish psychiatric hospitals only began to be developed in the 1990s. Nevertheless, the ideologies of deinstitutionalisation effected a transformation in

104 A.M. Keane (1987) 'Mental Health Policy in Scotland, 1908-1960' (PhD thesis: University of Edinburgh), p. 384.

${ }^{105}$ Carstairs' Reith Lectures in 1962 provide some insights into his views on mental health. G. Carstairs (1962) 'George Carstairs: This Island Now: The Reith Lectures', http://www.bbc.co.uk/programmes/p00h919f, accessed 22 March 2016.

106 J.K.W. Morrice (1966) 'Dingleton Hospital's Therapeutic Community', Psychiatric Services, 17, 140-43; S. Whiteley (2004) 'The Evolution of the Therapeutic Community', Psychiatric Quarterly, 75, 245. 
hospital practices, focussing attention on psychiatric rehabilitation and forging links with external organisations. ${ }^{107}$

The shape and extent of deinstitutionalisation differed in other countries and even within countries. In Canada, for instance, provincial jurisdiction over health meant that process of deinstitutionalisation differed markedly in each of the ten provinces. In Saskatchewan, situated in the heart of the western prairie provinces, the pioneering socialist Co-operative Commonwealth Federation (CCF) government of Tommy Douglas (1904-1986) began reorganising mental health services soon after it was elected in $1944 .{ }^{108}$ Such measures were part of Douglas' aim to institute a universal medical insurance system in Saskatchewan (Medicare), which began with the provision of public hospital care in 1947. By 1963, deinstitutionalisation was well under way, with the Saskatchewan Hospital in Weyburn, the largest hospital in the province (and the largest building in the province in the British Commonwealth at the time of its building in 1921, housing up to 2,500 patients) reducing its in-patient population by seventy-two per cent within five years. ${ }^{109}$ Quebec and Alberta would soon follow in rapidly deinstitutionalising its in-patient population. Prince Edward Island, British

${ }^{107}$ V. Long (2017) “"Heading Up a Blind Alley”? Scottish Psychiatric Hospitals in the Era of Deinstitutionalisation', History of Psychiatry [forthcoming? published online? doi? ]

${ }^{108}$ J.A. Mills (2007) 'Lessons from the Periphery: Psychiatry in Saskatchewan, Canada, 1944-1968', History of Psychiatry, 18, 179-201.

${ }^{109}$ Mills, 'Lessons from the Periphery', 185; C. Dooley (2011) 'The End of the Asylum (Town): Community Responses to the Depopulation and Closure of the Saskatchewan Hospital, Weyburn', Histoire Sociale/Social History, 44, 331-54. 
Columbia and New Brunswick, by contrast, experienced deinstitutionalisation more gradually. ${ }^{110}$

Regional differences in deinstitutionalisation were also present in Australia, where states were responsible for passing their own mental health legislation and where historical, cultural and racial tensions had a profound impact on the implementation of mental health reform. ${ }^{111}$ In contrast, New Zealand, which is more centralised, was able to carry out deinstitutionalisation further and more universally than most other western countries, a process that began with the 1969 Mental Health Act. ${ }^{112}$

In Europe, experiences of deinstitutionalisation also varied. In both East and West Germany, the legacy of the Second World War weighed heavily on psychiatric services. New community based services were introduced beginning in the $1960 \mathrm{~s}$, but mental hospitals remained the main locus of care until the 1980s. ${ }^{113}$ In France, where dispensaries and 'open departments' were founded on a local and voluntary and thus

${ }^{110}$ P. Sealy and P.C. Whitehead (2004) 'Forty Years of Deinstitutionalization of Psychiatric Services in Canada: An Empirical Assessment', Canadian Journal of Psychiatry, 49, 249-57.

${ }^{111}$ A. Rosen (2006) 'The Australian Experience of Deinstitutionalization: Interaction of Australian Culture with the Development and Reform of its Mental Health Services', Acta Psychiatrica Scandinavica, 113, 81-89.

112 A.J. O’Brien and R. Kydd (2013) ‘Compulsory Community Care in New Zealand Mental Health Legislation 1846-1992', Sage Open, http://sgo.sagepub.com/content/3/2/2158244013490175, accessed 22 March 2016.

${ }^{113}$ Schmiedebach and Priebe, 'Social Psychiatry in Germany in the Twentieth Century'. 
limited level already in the interwar period, ${ }^{114}$ psychiatric reform after the war centred on the policy of sectorisation. This did not aim at closing down mental hospitals, but at organising them better geographically and in relation to other services. ${ }^{115}$ As Nicolas Henckes describes in his chapter, however, deinstitutionalisation occurred nevertheless despite the ambitions of psychiatrists and the state to improve the psychiatric hospitals. In the Netherlands since the 1960s new outpatient services were available but they expanded to meet the needs of patients with serious disorders only in the 1980s and 1990s, when large psychiatric hospitals were downsized. ${ }^{116}$ In Finland, the process similarly occurred later, but rapidly, as the population in Finnish mental hospitals reduced by one-third during the 1990s. ${ }^{117}$ As Elena Trivelli describes in her chapter, Italy went further than all other countries, with Law 180 in 1978 beginning the twentyyear process during which all mental hospitals were shut. In Greece there was an early, albeit weak interest in community psychiatry since the late 1940s, but apart from a few isolated initiatives of community and outpatient treatment, psychiatric care was mainly provided in mental hospitals and private clinics until the 1980s. At that time deinstitutionalisation took off, but has been impeded by various factors, such as the lack

114 Nicolas Henckes, 'French deinstitutionalisation or the irony of success. Psychiatrists, the State and the transformation of the French psychiatric system, 19452010 , in this volume.

${ }^{115}$ Coffin, “"Misery” and "Revolution”: The Organisation of French Psychiatry, 19001980’.

${ }^{116}$ Oosterhuis, 'Between Institutional Psychiatry and Mental Health Care'.

${ }^{117}$ R.K. Salokangas and S. Saarinen (1998) 'Deinstitutionalization and Schizophrenia in Finland: I. Discharged Patients and their Care', Schizophrenia Bulletin, 24, 457-67. 
of trained personnel, the extensive bureaucracy, the mismanagement of funds and more recently, with the economic crisis, the decrease of public funding. ${ }^{118}$

\section{Outcomes}

The process of deinstitutionalisation has been appraised in different ways since the 1980s. Most commentators tend to agree that, although in many countries it has resulted in a decentralised, 'pluralistic mental health sector funded by a diversity of public and private programs', it has not meant the end of the mental hospital. ${ }^{119}$ On the contrary, in some countries, such as the US, the foundation of community services did not reduce rates of admission to public hospitals. ${ }^{120}$ The implementation of deinstitutionalisation programmes demonstrated the ongoing requirement for institutional care, as residential units and hospitals had specific functions which could not easily be replaced or removed. ${ }^{121}$ Indeed what has often happened was not deinstitutionalisation - the removal of patients from institutions - but trans-institutionalisation - the transfer of patients to alternative institutions, such as nursing homes, correctional institutions,

${ }^{118}$ A. Blue (1999) The Making of Greek Psychiatry (Athens: Exantas), pp. 119-25, in Greek and M. Mitrosyli (2015) Leros Mental Hospital and Reform. Public Policies, Institution, Community (Athens: Papazisi), in Greek.

${ }^{119}$ Mechanic and Rochefort, 'Deinstitutionalization: An Appraisal of Reform', quote on p. 322.

${ }^{120}$ Healy, The Creation of Psychopharmacology, p. 150; G.N. Grob (1996) 'The Severely and Chronically Mentally Ill in America: A Historical Perspective' in S.M. Soreff (ed.) Handbook for the Treatment of the Seriously Mentally Ill (Seattle: Hogrefe \& Huber), pp. 27-44.

${ }^{121}$ J.E. Gudeman and F.S. Miles (1984) 'Beyond Deinstitutionalization: A New Class of Facilities for the Mentally Ill', New England Journal of Medicine, 311, 832-36. 
private mental hospitals, general hospitals, board-and-care homes and other residential facilities. $^{122}$

Few service users mourn the demise of the old asylums. ${ }^{123}$ Nevertheless, for those who were truly deinstitutionalised, leaving institutions to live in the community, support has most often been inadequate. ${ }^{124}$ One reason for this has been the limited planning and resources for services and professional help in the community, but families and communities have also been opposed to deinstitutionalisation, arguing that at least some of the mentally ill were unable to live outside the institutions and/or posed a threat to the community. ${ }^{125}$ Exacerbated by cuts to the social welfare programmes in

${ }^{122}$ G. Grob (2005) 'The Transformation of Mental Health Policy in Twentieth-Century America' in Gijswijt-Hofstra, Oosterheis, Vijselaar and Freeman (eds.) Psychiatric Cultures Compared, pp. 141-61; Roberts and Kurtz, 'Historical Perspectives on the Care and Treatment of the Mentally Ill'; Mechanic and Rochefort, 'Deinstitutionalization: An Appraisal of Reform'; E. Shorter (1997) A History of Psychiatry: From the Era of the Asylum to the Age of Prozac (New York: John Wiley \& Sons), p. 281.

123 See, for example, P. Campbell (1992) 'A Survivor's View of Community Psychiatry', Journal of Mental Health, 1, 117-22; Barham, Closing the Asylum, pp. 3965. Diana Gittens' work indicates that the closure of some asylums was greeted with trepidation. D. Gittens (1998) Madness in its Place: Narratives of Severalls Hospital, 1913-1997 (London: Routledge).

124 Roberts and Kurtz, 'Historical Perspectives on the Care and Treatment of the Mentally Ill'.

${ }^{125}$ Fox, 'Debating Deinstitutionalisation'. 
many countries that began with the rise of neoliberal governments during the 1980s in North America, the UK and elsewhere, community care was increasingly perceived not as professional care delivered in the community but as informal, voluntary and unpaid care by the community, namely by relatives, friends and neighbours, care that was not always possible or optimal. As a result, the mentally ill were at greater risk of lacking the specialised treatment they needed, of losing genuine opportunities for kinship, friendship and neighbourhood networks and of facing the prospect of homelessness or incarceration. ${ }^{126}$ Homelessness, in particular, could cause a vicious cycles of episodic hospitalisations and unsupported discharges, creating significant problems for the administration of mental health services and adding to the already pronounced stigma faced by the mentally ill, as it strengthened the public perception of the mentally disordered as vagrant and possibly dangerous individuals. ${ }^{127}$ These limitations have led some to claim that 'deinstitutionalization remains an unfulfilled promise" ${ }^{128}$ or that 'the true "shame of the states" was not the asylum, as Albert Deutsch had contended in 1948 for the United States, but deinstitutionalisation. ${ }^{129}$ Indeed, the psychiatrist and

${ }^{126}$ C. Fox (2003) 'Debating Deinstitutionalisation: The Fire at Kew Cottages in 1996 and the Idea of Community', Health and History, 5, 37-59; P. Horden and R. Smith (1998) 'Introduction' in P. Horden and R. Smith (eds.) The Locus of Care: Families, Communities, Institutions, and the Provision of Welfare Since Antiquity (London: Routledge), pp. 1-18.

${ }^{127}$ H.R. Lamb and L.L. Bachrach (2001) ‘Some Perspectives on Deinstitutionalization', Psychiatric Services, 52, 1039-45.

${ }^{128}$ Mechanic and Rochefort, 'Deinstitutionalization: An Appraisal of Reform', 324.

${ }^{129}$ Shorter, A History of Psychiatry, p. 280. 
historian Trevor Turner has argued that 'a gradual return to more institutional provision seems likely', citing the backlash against community care fuelled by stories perceptions of the risk posed by some individuals who suffer from mental illness. ${ }^{130}$ However, this contention is hard to square with the continuing decline in the number of psychiatric inpatient beds, and even if deinstitutionalisation - at least in the way it was implemented - has failed in many respects, its predecessor, the asylum/residential hospital, has also been irreversibly discredited.

\section{Contents}

Post-War Psychiatry in the Western World: Deinstitutionalisation and After ${ }^{131}$ is divided into four sections, each examining deinstitutionalisation from a different perspective. The first section, 'Understanding deinstitutionalisation: culture, ideology and historiography' begins with John Burnham's argument that for deinstitutionalisation to occur, society had to undergo a 'tectonic shift' from a culture made up of producers, to one consisting of consumers. Prior to the deinstitutionalisation, asylums had been the spaces that housed society's unproductive members. The development of consumer culture in the post-war western world meant that patients no longer needed to be productive; they did, however, have to be consumers. Burnham's chapter, which draws on literature about consumer culture, illustrates how deinstitutionalisation not only reflected a monumental change in

${ }^{130}$ T. Turner (2004) 'The History of Deinstitutionalization and Reinstitutionalization', Psychiatry, 3:9, 1-4, 4.

${ }^{131}$ Our title nods to the work of noted British historian of psychiatry Kathleen Jones (1922-2010), particularly Jones, Asylums and After. 
psychiatric care, but also deep-seated transitions in terms of how an individual's contribution to society was measured.

Whereas Burnham's chapter deals with mainstream consumer culture and its relationship to deinstitutionalisation, Alexander Dunst analyses how radical ideas about psychiatry also informed the transformation of post-war psychiatry. Dunst's chapter examines American and German community magazines which were published by expatients and sympathetic mental health workers during the 1970s and early 1980s. Dunst argues that the magazines served a number of purposes to those who contributed to them and the thousands of people who read them. On the one hand, they helped to articulate the desires of radical therapists, many of whom saw patient liberation only in social transformation or revolution. But, on the other hand, the magazines were also therapeutic spaces in their own right, fuelling a more introverted self-help philosophy that distanced itself from politics.

Concluding the first section, the chapter by Megan Davies and Erika Dyck et al emphasises how deinstitutionalisation in Canada similarly had unintended consequences. Espousing a bottom-up approach that relies on the testimony and experiences of both patients and mental health practitioners, the authors portray deinstitutionalisation in Canada as a complex, contradictory process that varied across the ten provinces. Particularly notable is the authors' willingness to reflect upon how their project changed as they constantly sought to understand how deinstitutionalisation was 'experienced directly'. As a result, their chapter is as much about the methodology of mental health history and how to capture and value the voices of the voiceless as it is about an important chapter in the history of Canadian mental health.

The second section, 'Designing and Implementing Psychiatric Reform: Experiments, Opportunities and Oppositions' turns to four case studies of how 
deinstitutionalisation materialised in Europe. Christof Beyer begins by exploring the psychiatric reforms of Karl Peter Kisker at the Hanover Medical School during the 1960s and 1970s. Inspired by the social psychiatric reforms in the US and the UK, Kisker and his colleagues attempted to establish a community mental health approach, but their ambitious plans were undermined by the difficulties inherent in treating the most needy patients and the continued reliance on hospitals as the centre of 'community care'.

In France, as Nicolas Henckes explains, post-war mental health policy was dictated, as elsewhere, by concerns about the escalating rates of mental illness, but unlike many other countries, the mental hospital was viewed as part of the solution, rather than part of the problem. The policy of sectorisation, which was similar in nature to the catchment area policy in other jurisdictions, was intended to help improve and integrate outpatient services for the mentally ill, while retaining the hospital as the hub for such services. But, while hospitals continued to be constructed, the integration of services was left incomplete, resulting in 'an incredibly complex and fragmented landscape of institutions and services', rending many of the most vulnerable 'invisible'.

Addressing a more focussed case study, Val Harrington explores how community mental health services developed in Salford, Lancashire, arguing that it represented a rare example of how a local authority embodied the principles of the 1959 Mental Health Act (England and Wales). Seeking to elucidate why Salford was unique in this respect, Harrington examines the 'minutiae of change', ranging from the experiences, motivations and interactions of protagonists, such as Lance Burn, Salford's Medical Officer of Health, and the relevant social, political and geographical context. In so doing, she makes a compelling case for ensuring that local cases, such as Salford, inform grander narratives about deinstitutionalisation. 
The final chapter of this section turns to Greece, where Despo Kritsotaki demonstrates how the Centre for Mental Health and Research helped to make the case for deinstitutionalisation long before the process actually began in the 1980s. In addition to emphasising the impact of the Centre in gradually laying the groundwork for deinstitutionalisation by working with communities, Kritsotaki highlights how patients' families influenced the implementation on community mental health care, in some cases, obstructing it. Deinstitutionalisation eventually did occur in Greece, but it was a negotiated process that was dependent on changing social attitudes and the willingness of patients and families to accept it as a new approach to mental health care.

Our third section, 'New Conceptualisation of Therapy and Space', considers two novel therapeutic approaches that emerged in post-war Britain. John Stewart assesses how concerns about the 'maladjustment' of British children stimulated preventive approaches, most notably, child guidance. While children from dysfunctional backgrounds might previously have been removed from their home and institutionalised, Stewart describes how this policy was abandoned during the post-war period. Instead, psychiatrists, social workers and psychologists became convinced that they could re-educate parents and, thus, prevent or reverse the maladjustment of their children. Some aspects of child guidance were increasingly called into question: for example viewing the family, rather than socioeconomic factors, as the locus of pathology. Nonetheless, Stewart concludes that child guidance contributed to the demise of children's institutions.

Turning to a very different approach to mental illness, Cheryl McGeachan focuses on Kingsley Hall, the experimental community founded by R. D. Laing and Aaron Esterson during the 1960s. Employing the methodologies of geography, McGeachan analyses the sort of therapeutic space Laing and Esterson envisioned and 
what it actually became for the patients who lived there. McGeachan argues that such 'alternative conceptualisations of therapeutic "spaces" (both real and material, imagined and envisioned) matter in the exploration of the deinstitutionalisation process'. Such experiments were fraught with both practical and ethical challenges, may have been dismissed at the time and may have led to tragedies in some instances, but nevertheless represented a bold attempt to change thinking about mental illness and the therapeutic process, something that is worth remembering.

We conclude in our final section, 'After Deinstitutionalisation: Experiences, Challenges and Legacies' by presenting the aftermath of deinstitutionalisation in Italy, California and Australia. Elena Trivelli begins this section with her analysis of Italian deinstitutionalisation, specifically the work and legacy of Franco Basaglia. Law 180, which was passed in 1978 and is commonly known as 'the Basaglia Law', led to the replacement of Italian mental hospitals with community-based services. Focussing on Trieste, one of the cities in which Basaglia was based, Trivelli uses ethnography to argue that the way in which Basaglia's legacy has been invoked, mythologised and 'crystallised' runs counter to the way it should be interpreted, ending the revolution he sought to instigate rather prematurely.

In our penultimate chapter, Howard Padwa, Maria Meldrum, Jack Friedman and Joel Braslow consider how deinstitutionalisation has been experienced by three different mental health stakeholders in California: mental health administrators and providers, family members of the mentally ill and the mentally ill themselves. For administrators and providers, the adoption of neoliberal principles meant that community mental health care became as much about inculcating independence and autonomy as it was about fostering support and enabling therapeutic relationships. In response, family members reacted by forming advocacy groups that provided mutual 
support and lobbied to fight the stigma of mental illness and pushed for better public mental health services. Although these two stakeholders found promise in California's recovery model of mental health services, the authors' interviews with patients revealed that simple lack of support and care made it very difficult for them to gain the empowerment, independence and community connections required for recovery. Despite many attempts to reform and deinstitutionalise mental health services in California since the early 1970s, many of the problems remain, leaving patients struggling to receive the help they need.

With our final chapter, from Roslyn Burge, we almost come full circle. In it, she describes the process by which the Australian government repeatedly tried to shut down Callan Park, a mental hospital in New South Wales, eventually succeeding in 2008 in the hope of selling it off for profit. This was in spite of the protestations of local community residents who valued the hospital and advocated the expansion of mental health services. Rather than desiring deinstitutionalisation, the Friends of Callan Park desired improvements in institutional care, including making the hospital more integrated with the community in which it was enveloped.

By exploring how psychiatric institutions might have been reimagined, rather than replaced wholesale, Burge's chapter leaves us wondering about the lessons left by deinstitutionalisation. While most psychiatristsand patients would not welcome a return to a reliance on institutions, there may be a place for such facilities, however reimagined and reconfigured. The term 'asylum' may seem archaic and pejorative, but, during a time when discussion of 'asylum-seekers' dominates the news agenda in many western countries, perhaps we should reconsider what the word can also convey - a place of refuge. Community care might preferable in the long-term, but it is possible that people facing intractable psychiatric problems still need what asylum offers at difficult times 
in their life. Reminiscing about her time as a patient in Friern Hospital in the late 1980s, the historian Barbara Taylor describes how 'I could no longer do ordinary life, and giving up the struggle was an incalculable relief...Living in the bin was tough, but it gave me some shelter from my darkest self and, very importantly, the friendship of other patients'. ${ }^{132}$ While acknowledging the deficiencies of psychiatric hospital care, Taylor lambasts the 'individuated and disconnected' nature of community care. 'The much-touted independence of the community-based user', she observes, 'often equals a life of lonely isolation'. ${ }^{133}$

Equally, although deinstitutionalisation has been mercilessly attacked by its many critics, including the psychiatrist-cum-historian E. Fuller Torrey, it is likely that such assessments focus far too much on how deinstitutionalisation was carried out in practice, rather than the ideals upon which it was based. ${ }^{134}$ The high rates of serious mental illness amongst prisoners and the homeless is a terrible indictment of how the promoters of deinstitutionalisation failed to provide the supports required by countless psychiatric patients as the asylums emptied out and in the time since then. But such failures were not due to innate faults in the idea of deinstitutionalisation, but the inability and unwillingness of policy makers, politicians and the leaders of the mental health establishment to carry the process out as fully as was needed. Similarly, the notion that mental illness may be prevented may be just as elusive as it was in 1945 , but if as much resource and energy was dedicated to identifying and eliminating the causes of mental illness as is invested in the development of new psychiatric drugs,

\footnotetext{
132 Taylor, 'The Demise of the Asylum', pp. 212-13.

${ }^{133}$ Ibid, p 215.

134 Torrey, American Psychosis.
} 
perhaps prophylactic strategies would not be quite the mirage they are often described to be.

By compiling Post-War Psychiatry in the Western World: Deinstitutionalisation and After we aim to inspire more historians to ask searching questions about how ideas about mental health and psychiatry have evolved during the turbulent decades since the Second World War. ${ }^{135}$ We hope that, like many of the authors in this volume, they not only describe what has happened in the field of mental health, but also take the steps to inform debates about how policy and practice might improve in future. We admit that it has been impossible to cover all the themes, debates, places and people who shaped and were shaped by deinstitutionalisation, but encourage others to take up this task in the belief that this history will add immeasurably to how we understand and experience mental health and illness today and how we might improve the lives and prospects of the mentally ill in future.

135 This reflects the recent call by Greg Eghihan to 'deinstitutionalize' the history of psychiatry, that is, by exploring the history of psychiatry and mental health outside the asylum. G. Eghihan (2011) 'Deinstitutionalizing the History of Contemporary Psychiatry', History of Psychiatry, 22, 201-14. 